\title{
President's Column
}

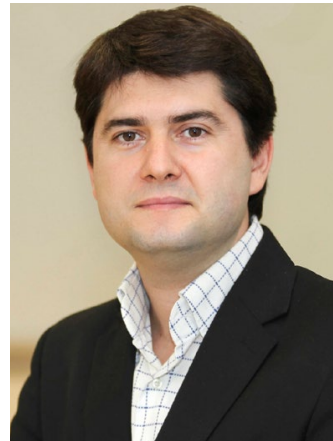

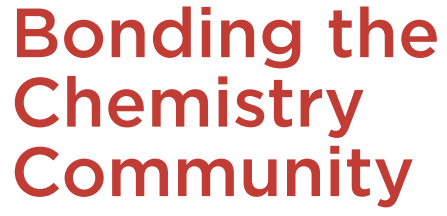

\author{
by Javier \\ García-Martínez
}

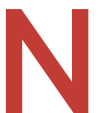

one could have imagined what history had in store for all of us when, just a couple of years ago, we were celebrating our Centenary and planning for the future of IUPAC. These past months, marked by a pandemic, have shown how fragile and interdependent we are. We have also learned the key role of science in understanding, tackling, and solving our most pressing challenges. Chemistry, in particular, is playing a central role in the fight against the coronavirus, from the production of disinfectants to the nanoparticles that carry the mRNA in the COVID-19 vaccines. However, this is not the last global challenge we will have to face and chemistry will continue to be essential in our fight against illness, hunger, and poverty.

Like so many other organizations, IUPAC too has had to adapt to a difficult time, when self-care and care for the people around us have been the top priority. A time in which we have had to learn on the fly how to work from home, adapt to new technologies, and be in countless virtual meetings while trying to balance our personal and professional life. Because of this, I would like to start this Column by acknowledging and thanking the excellent job that our staff has done to quickly adapt and to facilitate the work of all our volunteers. Our Secretariat has been above and beyond the call of duty, working tirelessly and with great efficiency to ensure that our organization not only carried on with its normal scientific activity but also held its first-ever virtual General Assembly, conducted a major review of its organizational structure, and significantly grew its online activities including the Global Women Breakfast, the Periodic Table Challenge, The Top Ten Emerging Technologies in Chemistry, and ChemVoices. I have no words that can thank our team enough for making all this possible. I would also like to take this opportunity to thank our past President, Chris Brett for leading during these difficult two years, our former Treasurer Colin Humphris, our Division Presidents, Committee Chairs, Titular and Associate Members, Affiliates, Task Force Members, partners, and all our volunteers for carrying on such a tremendous amount of work in a critical time under less than ideal conditions. Their availability and positive attitude speak volumes about their commitment to this Union and its mission.

However, we cannot continue operating in this way and, therefore, we must evaluate which activities and ways of working that we have implemented in the past months we should keep and which we should replace. To answer this question, we will be conducting a survey that is being designed to understand what our stakeholders liked about the way we operated during the last months, what they would like to change, and what they expect from us moving forward. With this initiative, we aim at capturing the lessons learned and at getting new ideas about the most efficient ways to communicate and engage with our stakeholders and among ourselves. This effort, which will be conducted by the Evaluation Committee led by Ehud Keinan, will greatly help us decide and define how to better use the new technologies while maintaining the clear benefits of in-person interaction. We are making every effort to facilitate the work of our volunteers and increase the impact and outreach of our scientific work. We are currently simplifying the project proposal format and submission process and from January 2022, Chemistry International will be freely available to all, which will help us to promote and give visility to our projects, activities, and recommendations.

I am delighted that some of the recommendations of the Review Group are already being implemented. Some are already a reality. For example, the new Committee on Ethics, Diversity, Equity, and Inclusion (CEDEI) has been established and its founding members have already been appointed. I would like to use this opportunity to thank Mary Garson for agreeing to chair this new Committee, which, I am sure, will be critically important to set up the guidelines that will help us to operate following our values and the highest standards. CEDEI will also produce recommendations on topics related to its mandate, which will be useful not only to IUPAC but to the entire chemistry community. Similarly, the IUPAC Centenary Endowment Fund was established last August during our General Assembly.* This represents a great opportunity and constitutes a new tool that will allow Fund Donors to support our work and to engage with the activities and initiatives of the Union.

Since our General Assembly, and in just a few months, we have done tremendous progress regarding the changes in our Statutes and Bylaws. This is not, by any means, an easy task but it is vital for the future of IUPAC. We have done our best to hear, debate, and 


\section{Officers}

Prof. Javier García-Martínez, Spain, President

Prof. Ehud Keinan, Israel, Vice President

include as many views as possible through multiple meetings and conversarions. I want to thank the members of the Executive Committee and the Bureau, and other stakeholders for their comments, suggestions, and feedback and to ask Council Delegates for their support during the special Council meeting that will be held in June, 2022. The simplification of our decision making process to create a more agile and lean organization will allow us to react faster and more effectively. At the same time that we are strengthening and streamlining our governance structure, we are making a significant effort to improve our communication and engagement with our NAOs and other stakeholders. In addition to the frequent meetings we are having with them thanks to the use of online tools, we are creating new opportunities to discuss and answer any questions in an informal format. This is the NAOs Forum, an online meeting that will be held in the off-years of our General Assembly to have a conversation and address any concerns that anyone may have. The experience of the last months has taught us that these informal and frequent dialogues are essential to have a fluid and engaging communication with our constituents. Similarly, during our General Assemblies, the IUPAC President will invite the representatives of all chemical societies and federations to a meeting, that we have called the Presidents Forum, to discuss topics of common interests, potential synergies, and opportunities for collaboration. One example of of these kinds of opportunities, which will involve many sister organizations, is the International Year of Basic Sciences for Sustainable Development. It provides us with a unique and far-reaching opportunity to raise awareness on how chemistry research and innovation are key in building a more resilient and circular economy. From reusable plastics to green ammonia, chemistry contributes to achieving the Sustainable Development Goals. These two innovations are, in fact, some of the top ten emerging technologies in chemistry that we have been highlighting since 2019 and that are having a major impact. This is an initiative that is promoting both IUPAC and the public image of chemistry helping us to reach wider audiences and other stakeholders. During our Centenary, we launched this and many other activities that have become so successful that we decided to continue them beyond 2019. This turned out to be an excellent decision because, during the pandemic, our online activities, including the Global Women Breakfast, the Periodic Table Challenge, and ChemVoices have grown beyond anyone's expectations and have opened many doors to IUPAC. We have now a much stronger and frequent collaboration with our sister organizations, especially 
with the International Younger Chemists Network, which is doing a terrific job and constitutes not only an opportunity but a priority for IUPAC.

But among all my priorities for this biennium, I want to highlight IUPAC Digital. Under this label, we include a series of actions that we are conducting at IUPAC to lead the digital chemistry space. This ranges from the creation of a chemical nomenclature for machines, namely the International Chemical Identifier $(\operatorname{InCh} \mid)$, to the adoption of the FAIR principles to ensure that all chemical data is Findable, Accessible, Interoperable, and Reusable. It became very clear during our last General Assembly, which had a session entirely devoted to IUPAC Digital that this is the way to go so IUPAC will keep leading the global chemistry community during the next decades, as most of the chemical information and data is now contained, stored, and shared in bits, not in paper. On this note, the digitalization of our Gold Book represents a unique opportunity to make all our content not only more accessible, but also more relevant, impactful, and useful. Finally, I want to bring here some of the conclusions of our recent World Chemistry Leadership Meeting that under the title "The Future of Chemistry in the World of Al" provided us with a clear and compelling vision for the future of IUPAC. This two-day online meeting, masterfully coordinated by
Chris Ober was a clear call to lead in this emerging field, which is already having a profound impact on chemistry discovery.

We are living in a time of uncertainty and profound changes, but also of great opportunities. Chemistry in general and IUPAC, in particular, are especially well-positioned to contribute to proving the solutions we need so urgently. I know I count on all of you to create an agile, effective, and inspiring organization, and to continue being the international community of chemists, widely recognized by its reputation, independence, and high standards. It will not be an easy task, that is for sure, but it is a challenge worth pursuing.

Javier García-Martínez <j.garcia@ua.es> is a Professor of Inorganic Chemistry and Director of the Molecular Nanotechnology Laboratory of the University of Alicante where he leads an international team working on the synthesis and application of nanostructured materials for the production of chemicals and energy. Javier is IUPAC President since January 2022. Previously, he served as Vice President and member of the Executive Committee, and as Titular Member and Vice-President of the Inorganic Chemistry Division.

*For a list of the actions taken at the IUPAC Council, held Virtual last August during the General Assembly, see https://iupac.org/ actions-taken-at-iupac-council-virtual-2021/

\section{Ethics, Diversity, Equity and Inclusion}

ome National Adhering Organizations or other organizations affiliated with IUPAC have in place committees or reference groups that address issues of ethics or diversity and inclusion. There are numerous womens' chemistry groups worldwide, many linked to the IUPAC Global Womens Breakfast series, and emerging chemists' groups, including the International Younger Chemists Network (IYCN). Specialist groupings include those for chemists of color, for less-able bodied chemists, or from LGBTQ communities. Each of these groupings requires our recognition, respect, and support. IUPAC is in the unique and privileged position to deliver global leadership on their behalf. There are still chemistry communities globally where the principles of equity are less well recognized, and IUPAC can provide support through networking and informal education or advice.

In August 2021, the 51st Council of IUPAC approved the formation of a Standing Committee on Ethics, Diversity, Equity and Inclusion (CEDEI). Plans for this newly established Standing Committee include providing guidelines for diversity and inclusiveness at IUPAC conferences, for editorial board memberships, task group memberships, and on selection panels (e.g. IUPAC awards). The role of CEDEI is outlined in the committee's terms of reference (see below).

IUPAC has a global base of members who are guided by the set of core values and behaviours identified in its strategic plan. Where an incident or behaviour inconsistent with these values is alleged, initial investigation should occur at the same level and with the people implicated involved, and only those incidents/behaviours unable to be resolved should be forarded, and in complete confidence, to CEDEl.

The current terms of reference for CEDEI are:

1. To provide independent advice to the President, Executive Committee, Executive Director, other Standing Committees, Divisions, and Commissions on matters relating to ethics, diversity, equity, and inclusion within the policies, business, and 